\title{
Research on Miniature Calibre Rail-Guns for the Mechanical Arm
}

\author{
Cao Ronggang , Zhang Guangwei and Su Ming \\ Beijing Institute of Technology5 South Zhongguancun Street, Haidian District, Beijing, 100081+86-1069818450, China
}

\begin{abstract}
Rail-gun should not only be used to military applications, but also can be developed as applications in the civilian aspects of the market. With the development of the electromagnetic launch technology, based on the similarity theory, using the existing rail-gun model to guide the construction of more economical miniature calibre rail-guns, and apply it in some machinery and equipment, this idea will open up a wider rail-gun application space. This article will focus on the feasibility of application of miniature calibre rail-guns in the mechanical arm. This paper designs the schematic diagram, then theoretical analyzes force conditions of the armature in the mechanical arm, calculates the possible range of the current amplitude and so on. The existing rail-gun model can be used to guides design the circuit diagram of the miniature calibre rail-gun. Based on the similarity theory and many simulation experiments, designed the experimental parameters of a miniature rail-gun and analyzed the current, Lorentz force, velocity, and location of the existing rail-gun and miniature rail-gun. The results show that the rail-gun launching technology applied to robot arms is feasibility. The application of miniature calibre rail-guns in the mechanical arm will benefit to the further development of rail-guns.
\end{abstract}

\section{Nomenclature}

$\mathrm{Uc}(\mathrm{t})=$ capacitors voltage,

$\mathrm{I}(\mathrm{t})=$ circuit current,

$\mathrm{R}_{0} \quad=$ equivalent initial resistor of circuit,

$\mathrm{R}(\mathrm{t}) \quad=$ rail resistor,

L0 = equivalent initial inductance of circuit,

$\mathrm{L}(\mathrm{t})=$ rail inductance,

$\mathrm{E}(\mathrm{t})=$ back electromotive force of armature,

$\mathrm{F}(\mathrm{t})=$ electromagnetic force,

L' = rail inductance gradient,

$\mathrm{m}=$ armature mass,

$\mathrm{a}(\mathrm{t})=$ armature acceleration,

$\mathrm{Fz} \quad=$ armature drag force,

$\mathrm{v}(\mathrm{t})=$ armature velocity,

$\mathrm{x}(\mathrm{t})=$ armature displacement,

$\mathrm{v}_{0}=$ initial velocity of the armature,

$\mathrm{x}_{0} \quad=$ resistance gradient of rail,

$\mathrm{U}_{0} \quad=$ charging voltage of the capacitors,

$\mathrm{C}=$ capacitors capacitance,

$$
\begin{array}{ll}
\mathrm{W} & =\text { thick of the sub-scale rail-gun, } \\
\mathrm{h} & =\text { tall of the sub-scale rail-gun, } \\
\mathrm{S} & =\text { long of the sub-scale rail-gun. }
\end{array}
$$

\section{Introduction}

Electromagnetic launching technology as a new launching technology is a general technology following the traditional chemical energy firing technology. According to the principle it can be divided into electromagnetic rail-guns and coil-guns. Electromagnetic rail-gun has been extensively studied for many years. Its principles and concepts were put forward in the late 19th century. French military has corresponding theoretical exploratory research at the beginning of 20th century. German military got financial aid to do the experimental verification of principles during World War II. Be restricted by the industry at that time and the processing means of basic industry such as the material, American experienced a long-term repeated verification after the Second War in world, and temporarily shelved the research on military application of electromagnetic launching technology in 1960s. Until the late of 1970 s, the results of successful experiments of Marshall are published, this new launching technology re-entered the military research program. And in 1980s started a new wave of study of rail-gun launching technology [1]. After entering the 1990s, with the development of rail-gun launching technology to the 
depth, military and many researchers found some serious problems that it is difficult to solve in short time on basic theories and applications, such as the problems of power supply and launcher life. From this period to 2007 or so, the main study of electromagnetic launching technology is solving key techniques. Electromagnetic gun oriented to military requirement is mainly concentrated on rail-guns. In the recent 10 years [2], with American navy stimulated rail-guns on a large scale electromagnetic launching technology has obtained considerable development, especially electromagnetic launcher. By the issued literatures we can see that the launcher life of rail-guns has been basically solved. Recently electromagnetic launching technology is expected to rapidly progress. Figure 1 shows the schematic diagram of rail-gun.

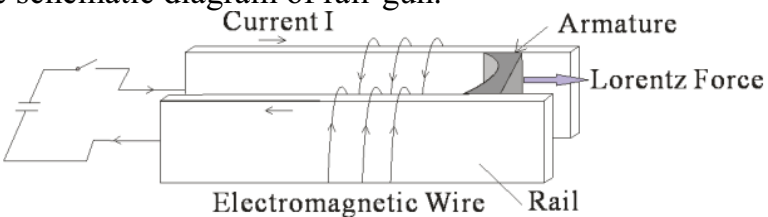

Figure 1. Schematic diagram of rail-gun

There are many kinds of the transmission mechanism of miniature manipulate at present. They can be roughly divided into electric drive, pressure drive, and internal combustion engine drive. Motor drive is the common way of electric drive, such as asynchronous and synchronous motor drive and stepper motor drive. The usual form of pressure drive is hydraulic or pneumatic actuators. And internal combustion engine drive generally used micro internal combustion engines. Rail-guns as the power mechanism of mechanical arm is belong to direct linear drives. The structural of the traditional linear motor or electron pusher mainly are coil-guns or are finished by the mechanical structure of straight line mechanism converted by rotating mechanism. The schematic diagram of linear motor is shown in figure 2. Comparing with rotating mechanism and coil-type linear motor, the rail-gun has the advantages of simple structure and easy control while is applied to drive manipulators.

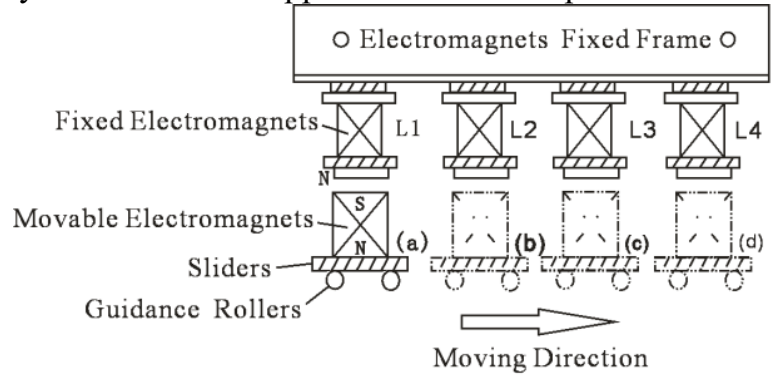

Figure 2. Schematic diagram of linear motor

Electromagnetic launching technology is mainly driven by the military demand. The research focus and the hotspot in current study are both placed on military applications. The study is developed from medium-small caliber to large caliber. This paper mainly studies the design and computation of the launching technology of micro caliber rail-gun launcher and launch system in the micro movable and manipulator. Based on design and analysis of the manipulator system of micro caliber rail-gun, this paper gained the appropriate electric parameters by researching and analyzing the characteristics, and theory analyzing the force condition of armature.

\section{Analysis the circuit parameter of miniature calibre rail-gun}

The storage energy of pulsed power supply system of rail-gun could reach mega-joules, the length of the launcher could be up to several meters, and the calibre of rail-gun was usually several tens of millimeters. With one experimental device as example, the parameters of the rail-gun is line in Table 1. For the electromagnetic force endured by armature during the acceleration is great, the friction force can be assumed to 0 . Figure 3 shows the rail-gun equivalent circuit model of the system [3] [4]. And figure 4 shows the simplified equivalent circuit of rail-gun.

Table 1. Railgun parameters

\begin{tabular}{|c|c|}
\hline Parameters & Values \\
\hline Capacitance configuration & $2 \mathrm{mF}$ \\
\hline charge voltage & $8 \mathrm{KV}$ \\
\hline Rail length & $5000 \mathrm{~mm}$ \\
\hline Armature mass & $0.1 \mathrm{Kg}$ \\
\hline Pulse-shaping inductor & $50 \mu \mathrm{H}$ \\
\hline Capacitor resistance & $20 \mathrm{~m} \Omega$ \\
\hline Inductor resistance & $10 \mathrm{~m} \Omega$ \\
\hline Cable resistance & $2 \mathrm{~m} \Omega / \mathrm{m}$ \\
\hline Inductance gradient & $0.5 \mu \mathrm{H} / \mathrm{m}$ \\
\hline Resistance gradient & $0.1 \mathrm{~m} \Omega / \mathrm{m}$ \\
\hline
\end{tabular}

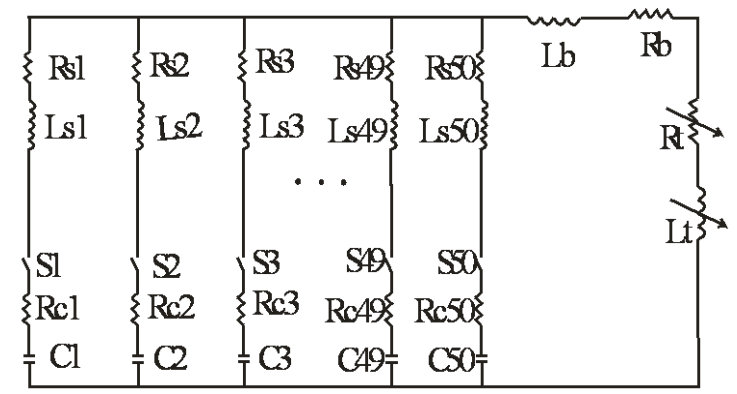

Figure 3. Rail-gun equivalent circuit model configuration

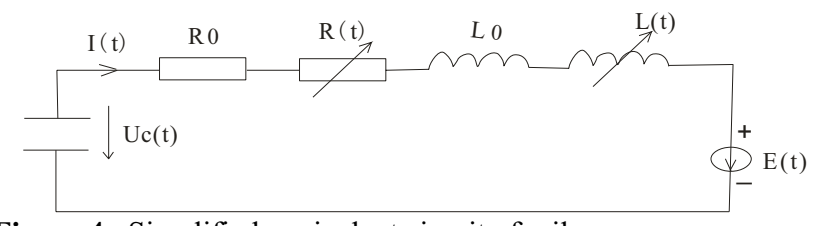

Figure 4. Simplified equivalent circuit of rail-gun

The equivalent circuit equation may be written: 


$$
U_{c}(t)-E(t)=\left(\mathrm{R}(t)+\mathrm{R}_{0}\right) \mathrm{I}(t)+\frac{d}{d t}\left[\left(\mathrm{~L}(t)+\mathrm{L}_{0}\right) \mathrm{I}(t)\right]
$$

The electromagnetic force on armature can be expressed as

$$
F(t)=\frac{L^{\prime}}{2} \mathrm{I}^{2}(t)
$$

The acceleration equation can be written as

$$
F(t)-F_{z}=m a(t)
$$

The armature velocity $\mathrm{v}(\mathrm{t})$, the armature displacement $\mathrm{x}(\mathrm{t})$, the rail resistance $\mathrm{R}(\mathrm{t})$, and the rail inductance $\mathrm{L}(\mathrm{t})$ can be derived based on the equation (2) (3)

$$
\begin{gathered}
\mathrm{v}(t)=v_{0}-\frac{F_{\mathrm{z}}}{m}+\frac{L^{\prime}}{2 m} \int_{0}^{t} \mathrm{I}^{2}(t) d t \\
x(t)=x_{0}+v_{0} t-\frac{F_{\mathrm{z}}}{m} t+\frac{L^{\prime}}{2 m} \int_{0}^{t}\left(\int_{0}^{t} \mathrm{I}^{2}(t) d t\right) d t \\
\mathrm{R}(t)=2 \mathrm{R}^{\prime} x_{0}+2 \mathrm{R}^{\prime}\left[v_{0} t-\frac{F_{\mathrm{z}}}{m} t+\frac{L^{\prime}}{2 m} \int_{0}^{t}\left(\int_{0}^{t} \mathrm{I}^{2}(t) d t\right) d t\right] \\
L(t)=L^{\prime} x_{0}+L^{\prime}\left[v_{0} t-\frac{F_{\mathrm{z}}}{m} t+\frac{L^{\prime}}{2 m} \int_{0}^{t}\left(\int_{0}^{t} \mathrm{I}^{2}(t) d t\right) d t\right]
\end{gathered}
$$

For the back electromotive force of armature is proportional to the product of magnetic induction intensity and velocity, and the magnetic induction intensity is proportional to circuit current, so the back electromotive force of armature can be written as ${ }^{[5][6]}$

$$
E(t)=\frac{L^{\prime}}{2} \mathrm{I}(t)\left(v_{0}-\frac{F_{\mathrm{z}}}{m}+\frac{L^{\prime}}{2 m} \int_{0}^{t} \mathrm{I}^{2}(t) d t\right)
$$

Based on the relation of the charge of capacitors, the voltage of capacitors can be written as

$$
U_{c}(t)=U_{0}-\frac{1}{C} \int_{0}^{t} \mathrm{I}(t) d t
$$

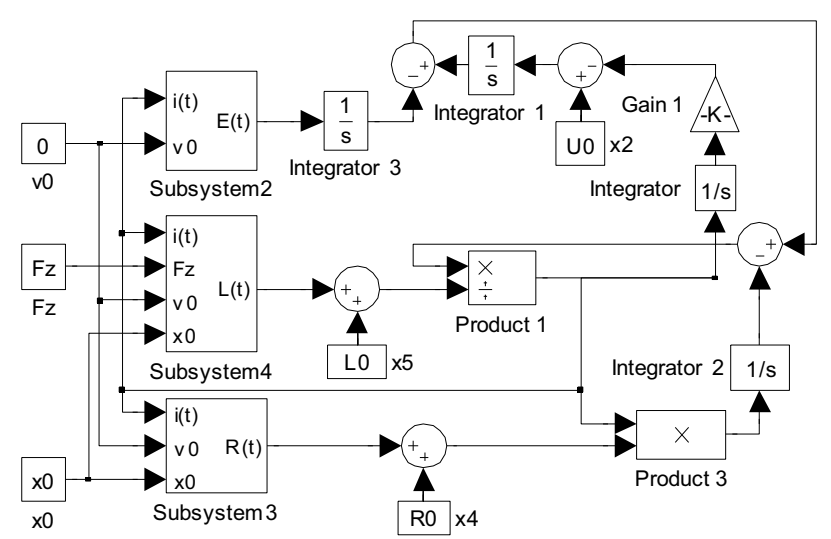

Figure 5. Simulation model for the circuit

The electric circuit simulation of the rail-gun was carried out by using Simulink. Simulink is a component of
MATLAB, which provides an integrated environment for dynamic system modeling, simulation and comprehensive analysis [7]. Based on the modeling and analysis of electric circuit parameters, this paper deduced the integrate form of equation (1), and then putted up a simulation model of the circuit. Figure 5 shows the simulation model.

In Figure 5, Ls was the pulse-shaping inductance of circuit, Lb was the initial inductance in the rail, Rs was the total resistance in the capacitor branch, $\mathrm{Rb}$ was the initial resistance in the rail. Figure 6 shown the simulation results, included the current, velocity, and the location of armature. In figure 6, the first figure shows that the discharge time of the capacitor was $\sim 1.5 \mathrm{~ms}$, the peak current was $\sim 0.8 \mathrm{MA}$. The second figure shows that the maximum Lorentz force of armature was about $1.65 * 105 \mathrm{~N}$. The third figure shown that the velocity of armature reached the maximum after the capacitor discharged. The fourth figure shown that there was a acceleration process of armature during the capacitor discharging, and then the armature was moving with uniform velocities in straight lines. The barrel residence time of armature was $4.8 \mathrm{~ms}$. As shown in figure 6 , the simulation results did describe the experimental data quite well.

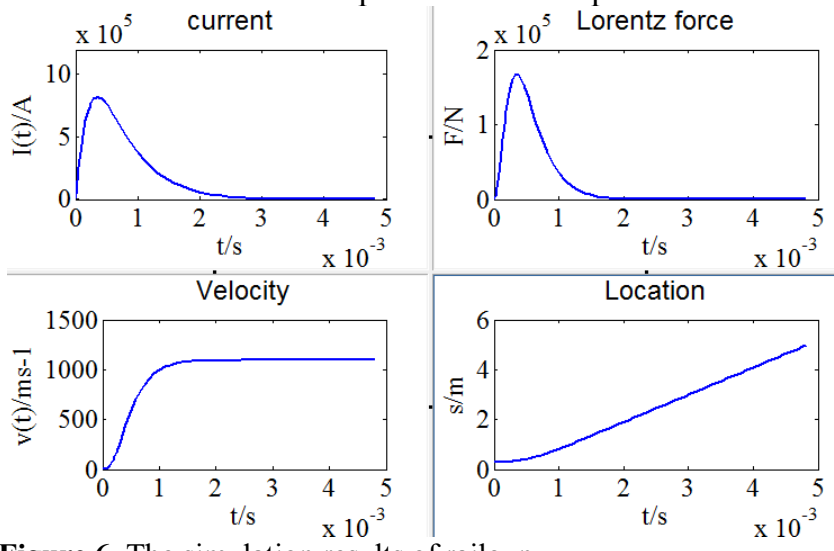

Figure 6. The simulation results of railgun

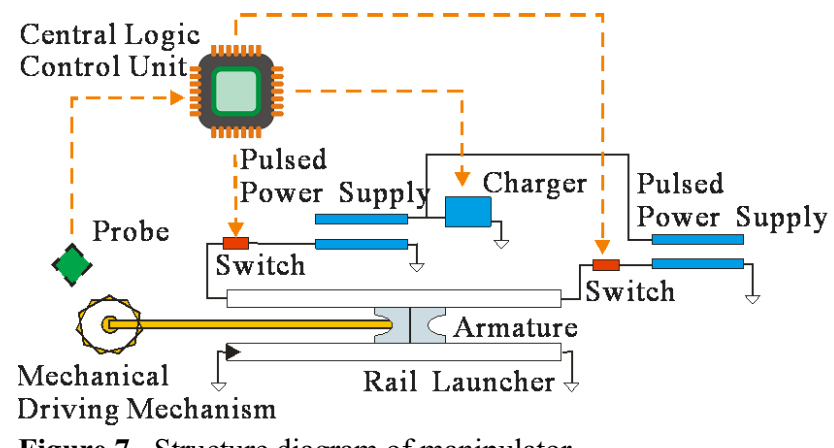

Figure 7. Structure diagram of manipulator

\section{Design of manipulator system based on the electromagnetic launching technology}

Rail-guns need extremely high pulse currents, and make strict demands on the power supply. Considering the miniature caliber rail-gun doesn't need high muzzle velocity and acceleration of armature compared with the rail-gun for 
military requirements, this paper using the enhanced rail-gun and the enhanced armature of high field magnets. Be restricted by the future application requirement of manipulator, the method of connecting pulsed power supply with the muzzle and the breech respectively is applied to realize the reciprocate motion of armature. Figure 7 shows the structure diagram. And the system diagram of manipulator is shown in Figure 8.

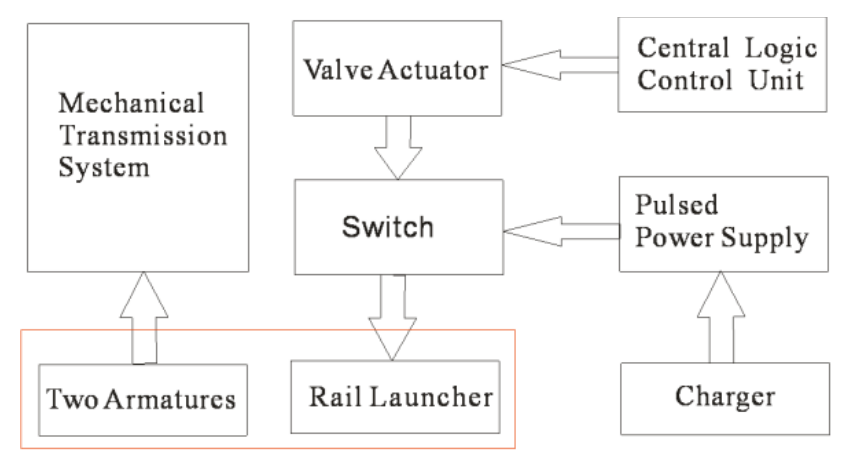

Figure 8. System diagram of manipulator

\subsection{Parameter Calculation}

The drive system based on rail-gun has the simple control mechanism and control Strategy for it only need to control the firing time, and don't need to keep accurate timing control just like linear motor and coil-gun. The manipulator structure which is suitable for the future engineering application used the method, which parallels many manipulators with redundancy control, to completed different extension angle and displacement of manipulators with different measurement range. By the statements as above, we can find out that the manipulator system with micro rail-gun has advantages of simple structure and simple control.

In order to study the feasibility of the rail-gun launching technology applied to robot arms, this paper derived the sub-scale rail-gun parameters based on the scaling method ${ }^{[8]}$. We obtained for subscale a 200-mm-long, 8-mm square-bore gun with rail dimensions of $8 \mathrm{~mm} * 2 \mathrm{~mm} * 200 \mathrm{~mm}$. The scaled launch package mass was $0.8 \mathrm{~g}$, the armature resistance was $30 \mathrm{~m} \Omega$. The resistance of conductor was $0.4 \mathrm{~m} \Omega / \mathrm{m}$, and the value of the pulse-shaping inductor was $20 \mu \mathrm{H}$. Based on the equation $R^{\prime}=R / L=\rho / S$ the resistance gradient was derived as $2.5 \mathrm{~m} \Omega / \mathrm{m}$.

In the case of high frequency magnetic field distribution the calculation formulas of the inductance gradient of the electromagnetic launcher with a rectangular aperture can be written as

$$
\begin{gathered}
L^{\prime}=\left(\left(0.4406-0.0777 \ln \left(F_{1}\right)\right) \ln \left(\mathrm{F}_{2}\right)\right) \\
\mathrm{F}_{1}=1+3.397(w / h)-0.06603(w / h)(s / h) \\
\mathrm{F}_{2}=1.0077+2.7437(s / h)+0.02209(w / h)+0.02637(w / h)(s / h)
\end{gathered}
$$

The inductance gradient was derived as $0.5 \mu \mathrm{H} / \mathrm{m}$. It can be known by many simulations that increasing voltage and capacitive value can improve the bearing tension force of the miniature rail-gun when the shape and the materials of the rail-gun were determined. However, the oversize voltage would cause oversize current, and the oversize capacitance would cause over lowing energy utilization ratio. In this paper the sub-scale system consisted of 50 capacitors, the charging voltage of capacitor was set to $18.09 \mathrm{~V}$, and the capacitance of capacitor was set to $15 \mathrm{mf}$, the resistance of capacitor was $11.6 \mathrm{~m} \Omega$. The resistance force of armature was assumed to be $0.003 \mathrm{~N}$ in order to reach the purpose that the armature could move to muzzle in 0.1 second.

\subsection{Simulation analysis}

The simulation results of resistance force existing in the sub-scale railgun was shown in Figure 9, including the current, the resultant force, the velocity, and the location of armature.

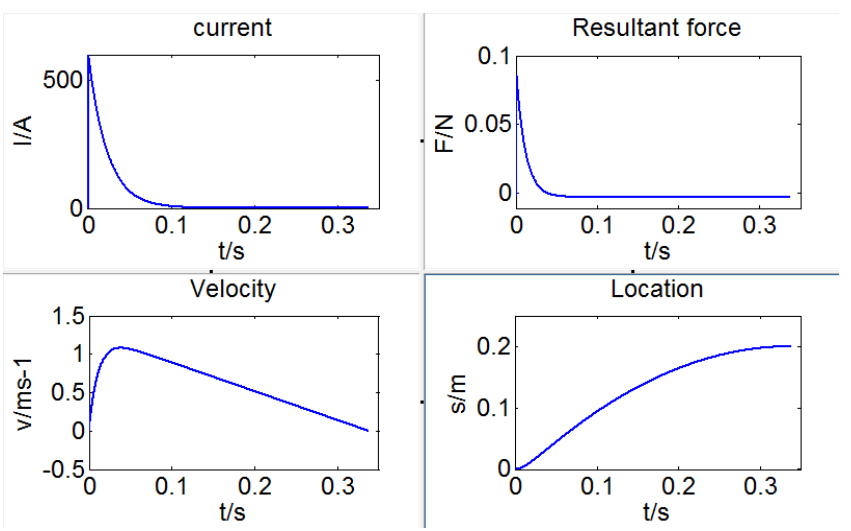

Figure 9. Simulation results of the sub-scale

As shown in the figure 9, (the first figure shows the discharge time of the capacitor, the second figure shows the resultant force of armature, the third figure shows the velocity of armature, the fourth figure shows the location of armature).the discharge time of the sub-scale rail-gun was $\sim 0.1 \mathrm{~s}$, the peak current was $\sim 550 \mathrm{~A}$, the maximum resultant force of armature was $\sim 0.08 \mathrm{~N}$, when the resultant force reduced to $0 \mathrm{~N}$, the velocity of armature reached the maximum, which was $1.1 \mathrm{~m} / \mathrm{s}-1$, the muzzle time of armature was $0.338 \mathrm{~s}$, it's also the time for the velocity reduced to $0 \mathrm{~m} / \mathrm{s}-1$.

In this simulation, the peak current was about 550A, it was still great and may cause unsafe problem. While the tension force of the miniature rail-gun was too small. Increasing inductance gradient and current can improve the bearing Lorentz force of armature was known by the equation (2), in this way the tension force of the miniature rail-gun can increased. The inductance gradient can be increased by a change of the rail geometric parameters. 


\section{Conclusion}

The theoretical analysis and the result of simulation show that the rail-gun launching technology applied to robot arms is feasibility. But the shape and the materials of the miniature rail-gun should be change. For the armature can easily get larger Lorentz force from coil-guns, change the rail-guns to coil-guns may can also suitable.

\section{Acknowledgment}

This work is supported by the National Natural Science Foundation of China under Grant 51407010.

\section{References}

1. H. D. Fair. Progress in Electromagnetic Launch Science and Technology. IEEE Trans Magn. 43,1,93-98, (2007)

2. H. D. Fair. Advances in Electromagnetic Launch Science and Technology and its Applications. IEEE Trans Magn. 44, 1, 225-230, (2009)
3. N. Pan, X. J. Han. Electromagnetic Railgun Circuit Simulation Modeling. Ship Science and Technology. 35, 10, 101-105, (2013)

4. P. Z. Liu, X. J. Yu, J. Li and S. Z. Li. Energy Conversion Efficiency of Electromagnetic Launcher with Capacitor-based Pulsed Power System. IEEE T Plasma SCI. 41, 5, 1295-1299, (2013)

5. G. Q. Chen, H. Y. Zhang, Y. H. Wang, X. L. Wei and C. Z. Fang. The Circuit Theory Analysis and Dynamic Aimulation for the Capacitor Drived Railgun. Electric Machines and Control. 10, 1, 23-26, (2006)

6. G. Q. Chen, Y. H. Wang, X. L. Wei and H. Y. Zhang. Computer Simulation of Electromagnetic Process in the Capacitor Drive Rail gun. Transactions of China Electrotechnical Society. 21, 4, 68-71, (2007)

7. J. Yao and S. H. Ma. Simulink Simulation and Modeling. Xi'an: Xidian University press. (2007)

8. L. W. Jin, J. Li and B. Lei. Approximate Field Scaling of Railgun Launcher Under the Condition of Matching Projectile Dynamic Parameters. IEEE T Plasma SCI. 43, 9, 3286-3292, (2015) 